\title{
Giant Star-shaped Nitrogen-doped Nanographenes
}

\author{
Juan P. Mora-Fuentes, ${ }^{[a]}$ Alberto Riaño-Carnerero, ${ }^{[a]}$ Diego Cortizo-Lacalle, ${ }^{[a]}$ Akinori Saeki, ${ }^{[b]}$ Manuel \\ Melle-Franco, ${ }^{*[c]}$ Aurelio Mateo-Alonso*[a,d]
}

\begin{abstract}
Star-shaped nanographenes are large monodisperse polycyclic aromatic hydrocarbons that extend in size beyond the nanometer and have shown a lot of promise in a wide range of applications including electronics, energy conversion and sensing. Herein we report a new family of giant star-shaped $\mathrm{N}$-doped nanographenes with diameters up to $6.5 \mathrm{~nm}$. Furthermore, the high solubility of this SNG family in neutral organic solvents at room temperature allowed a complete structural, optoelectronic and electrochemical characterisation, which together with charge transport studies illustrate their n-type semiconducting character.
\end{abstract}

Nanographenes (NGs) are large monodisperse polycyclic aromatic hydrocarbons that extend in size beyond the nanometer and have shown a lot of promise in a wide range of applications including electronics, photonics, and energy. ${ }^{[1]}$ Atomically-precise control over the NG structure is crucial to fully exploit their potential. For instance, by controlling the number of rings, their arrangement, heteroatom-doping and substitution, it is possible to fine-tune their energy levels and therefore, modulate electron affinities, ionization potentials, energy gaps, absorption and emission properties, among others.

Among these, planar threefold symmetric star-shaped nanographenes (SNGs), such as starphenes, cloverphenes and their extended derivatives (Figure 1) ${ }^{[2]}$ have shown a prominent position as materials for charge transport, energy conversion and storage, light-emitting and sensing applications. ${ }^{[3]}$ However, even if, there have been very impressive advances in recent years and large SNGs diameters reaching $3.0 \mathrm{~nm}\left(C_{150}\right)$ have been reported by solution synthesis, ${ }^{[2 \mathrm{c}-\mathrm{e}, 2 \mathrm{j}-1]}$ the largest soluble SNG that has been fully characterised presents a diameter of $2.8 \mathrm{~nm}\left(\mathrm{C}_{66}\right) .^{[2 \mathrm{~m}]}$ This is because of the lack of solubility of planar $\pi$ systems that extend in two dimensions, which tend to aggregate strongly by $\pi$-stacking in solution (Figure 1). In fact, the synthesis of extended SNGs is still a challenging task that requires dealing with insoluble intermediates and products, which overall makes synthesis, purification, characterisation and processing difficult, slowing down the exploration of their

[a] Prof. Dr. A. Mateo-Alonso, J.P. Mora-Fuentes, Dr. A. RiañoCarnerero and Dr. D. Cortizo-Lacalle

POLYMAT, University of the Basque Country UPVIEHU

Avenida de Tolosa 72, E-20018 Donostia-San Sebastian, Spain

Fax: (+)34 943506062

E-mail: amateo@polymat.eu

Homepage: www.polymat.eu

[b] Prof. Dr. A. Saeki

Department of Applied Chemistry, Graduate School of Engineering,

Osaka University

Suita, Osaka 565-0871, Japan.

[c] Prof. Dr. M. Melle-Franco

CICECO - Aveiro Institute of Materials, Department of Chemistry, University of Aveiro

3810-193 Aveiro, Portugal

E-mail: manuelmelle.research@gmail.com

[d] Prof. Dr. A. Mateo-Alonso

Ikerbasque, Basque Foundation for Science

E-48011 Bilbao, Spain fundamental properties and the development of potential applications.

Herein we report a new family of giant SNGs that show diameters exceeding those of the largest SNGs $(3 \mathrm{~nm})$ and that have been fully characterised thanks to their high solubility (Figure 1). For instance, the first generation of this family (SNG$\mathbf{G}_{1}$ ) shows a diameter of $4.1 \mathrm{~nm}$, and remarkably, the second generation $\left(\mathbf{S N G}-\mathbf{G}_{2}\right.$ ) shows a diameter of $6.5 \mathrm{~nm}$. As we show below, the synthesis of this SNG family is not trivial and requires the careful design of a key $\mathrm{C}_{3}$-symmetrical precursor $\left(\mathbf{S N G}-\mathbf{G}_{\mathbf{0}}\right.$ ), from which the aromatic core can be then extended radially. Furthermore, the high solubility of this SNG family in neutral organic solvents at room temperature allowed a complete structural, optoelectronic and electrochemical characterisation that together with charge transport studies illustrate their $n$-type semiconducting character

On a first approach, we aimed at synthesising SNGs by cyclocondensation of precursor $\mathbf{A}^{[4]}$ to the commercially available cyclohexane-1,2,3,4,5,6-hexaone (HKT) (Scheme 1a), which has been broadly used for the synthesis of hexaazatriphenylenes and hexaazatrinaphthylenes. ${ }^{[3 a}$, 5] We selected precursor A, which consists on a dibenzodiazatetracene core with terminal protected ketones in the pyrene end and diamino groups at the quinoxaline end that enables an iterative reaction scheme, as it can be assembled with itself by rounds of cyclocondensation/deprotection reactions. In addition, A possesses a combination of tert-butyl and tri-isobutylsilyl (TIBS) groups that have proven to render large NGs soluble. However, when we carried out the cyclocondensation between building block $\mathbf{A}$ and HKT in the solvent mixtures typically used for this type of cyclocondensations, the reaction did not provide the expected cycloadduct $\mathbf{B}$ and instead, yielded an inseparable mixture of compounds. When this mixture was exposed to Bunz oxidation conditions $\left(\mathrm{MnO}_{2}\right),{ }^{[6]}$ it evolved into adduct $\mathbf{C}$ with a linear $C_{2}$ ribbon-like structure (Scheme 1a). The formation of the $C_{2}$ instead of the $C_{3}$ condensation adduct was surprising since some of us have previously reported the synthesis of the structurally equivalent hexa(TIBS)acetylenesubstituted hexaazatrinaphthylene..$^{[7]}$ Nevertheless, the formation of the $C_{2}$ adduct can be rationalised in terms of the low nucleophilicity of the diamines on the quinoxaline residue of $\mathbf{A}$, which is unable to overcome the steric hinderance present on the $C_{3}$ adduct, giving rise to a mixture of linear $C_{2}$ dihydro species that are aromatised afterwards to $\mathbf{C}$ by $\mathrm{MnO}_{2}$, in line with several cases that have been noted in recent literature. ${ }^{[8]}$

At this stage, we changed strategy (Scheme 1b) and designed a new $C_{3}$ symmetrical precursor in which the three sets of diones are far apart from each other and at the same time are close to tert-butyl solubilizing groups that should not interfere sterically with the TIBS groups present at $\mathbf{A}$ during the triple cyclocondensation step. We therefore condensed pyrene diketone $\mathbf{D}^{[9]}$ that can be obtained in 4 steps from pyrene and 


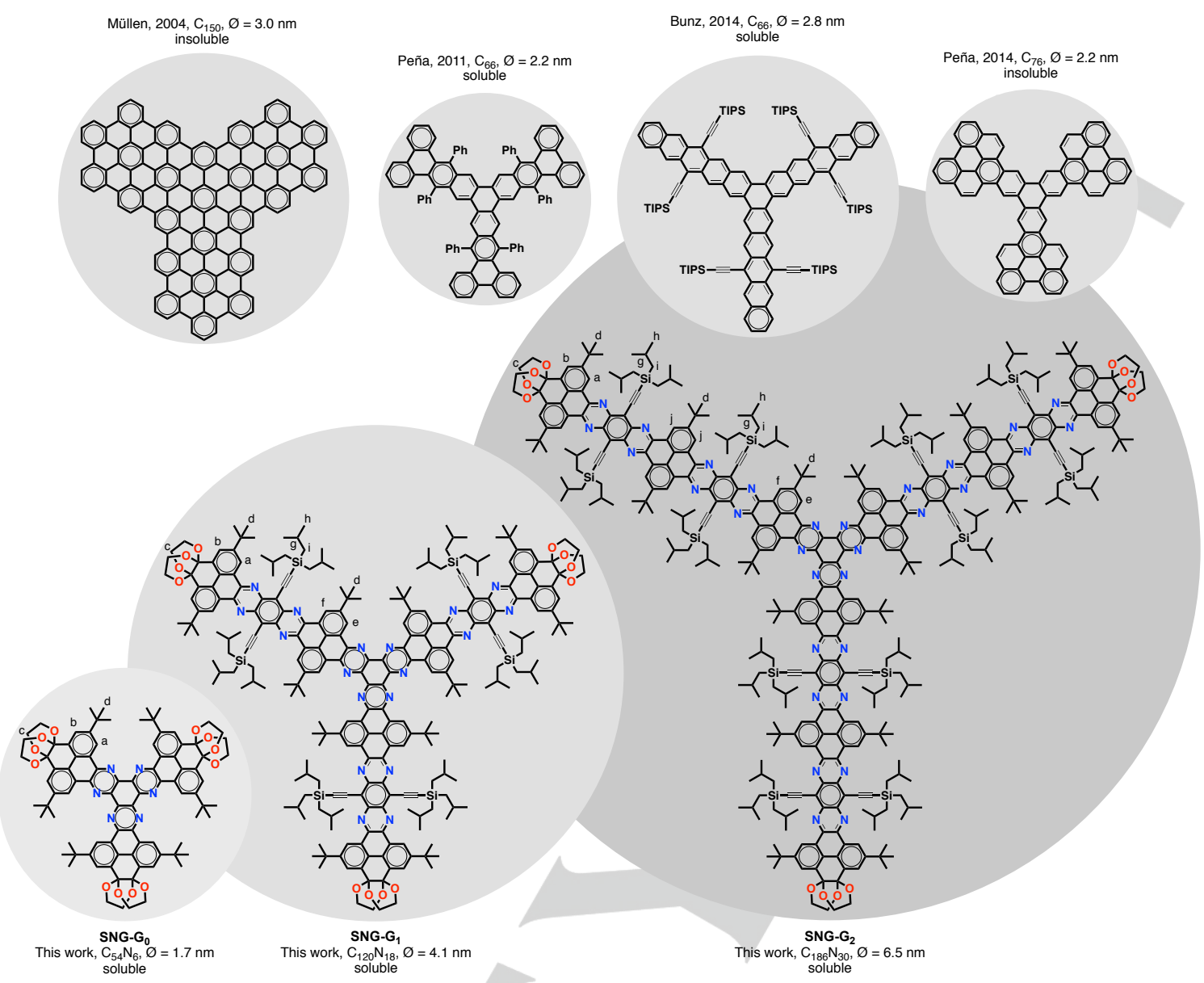

Figure 1. The structure of SNG-G $\mathbf{G}_{0} \mathbf{S N G}-\mathbf{G}_{1}$ and $\mathbf{S N G}-\mathbf{G}_{2}$, in comparison to representative SNGs synthesised by solution methods. Molecular formulas correspond to those of the aromatic core only.

$1,2,3,4,5,6$-hexaaminobenzene $(\mathbf{H A B})^{[5]}$ that can be obtained in 3 steps from 1,3,5-trichlorobenzene. The cyclocondensation proceeded without problems and yielded the hexaone-protected precursor SNG-G $\mathbf{G}_{0}$ in a good yield (45\%). The deprotection of the terminal $o$-diones in the presence of TFA and water yielded the hexaone-terminated precursor SNG-G $-\mathbf{Q} \quad(70 \%)$. The cyclocondensation reaction between $A$ and $\mathbf{S N G}-\mathbf{G}_{0}-\mathbf{Q}$ proceeded without any problems and yielded SNG-G $\mathbf{S}_{1}$ after chromatographic purification $(32 \%)$. The deprotection of the terminal diones in water/TFA, followed by cyclocondensation with $\mathbf{A}$ yielded the desired SNG-G $\mathbf{2}(38 \%)$.

The whole SNG series were remarkably soluble in toluene, and chlorinated solvents at room temperature and we were able to establish unambiguously their structure by ${ }^{1} \mathrm{H}-\mathrm{NMR}$ and ${ }^{13} \mathrm{C}$ NMR spectroscopy and matrix-assisted laser desorption/ionization time of flight high-resolution mass spectrometry (MALDI-TOF HRMS). The ${ }^{1} \mathrm{H}$-NMR and ${ }^{13} \mathrm{C}-\mathrm{NMR}$ spectra showed remarkably sharp signals that allowed confirming the structure in all the SNGs, illustrating the high solubility of the whole series. For instance, the integration of ${ }^{1} \mathrm{H}$ NMR signals are in agreement with the structures of the SNGs (Figure 2a), integrating 6 protons for the aromatic signals $a$ and $b$ in SNG-G $\mathbf{G}_{0} \mathbf{S N G}-\mathbf{G}_{1}$ and $\mathbf{S N G}-\mathbf{G}_{2}, 6$ protons for the aromatic signals $e$ and $f$ in the case of $\mathbf{S N G}-\mathbf{G}_{1}$ and $\mathbf{S N G}-\mathbf{G}_{2}, 12$ protons for the aromatic signal $j$ in the case of SNG-G $\mathbf{G}_{2}$ (the assignments correspond to the lettering in Figure 1). While in SNG-G, $\mathbf{S}$, $\mathbf{G}_{1}$ and $\mathbf{S N G}-\mathbf{G}_{2}, 12$ protons for the terminal diketal signals $C$ were observed in all cases, which is also consistent with the structure. ${ }^{[10]}$ Further evidence of the successful preparation of the SNGs came from MALDI-TOF HRMS that show ion peak masses $(\mathrm{M}+\mathrm{Ag})^{+}$of $1553.5692,4211.1790$, and $6868.7884 \mathrm{Da}$, respectively for SNG-G $\mathbf{S}_{\mathbf{0}} \mathbf{S N G}-\mathbf{G}_{1}$ and $\mathbf{S N G}-\mathbf{G}_{2}$, that matched with the expected mass. The isotopic distributions could be only recorded for SNG-G $\mathbf{G}_{0}$ and $\mathbf{S N G}-\mathbf{G}_{1}$ due to the high molecular weight of SNG-G $\mathbf{G}_{2}$, which is at the detection limit of the technique that illustrates the extremely high molecular weight of these monodisperse systems. Since we were not able to obtain single crystals suitable for $\mathrm{X}$-ray diffraction, semiempirical quantum mechanics were used to investigate the structure of SNGs with the GFN-xTB method (Geometry, Frequency, Non-covalent, eXtended Tight-Binding) that allows computing efficiently high molecular weight systems with thousands of atoms. ${ }^{[4,11]}$ The simulations show that the SNG series can adopt a plethora of slightly twisted conformations as the result of the bulkiness and the TIBS groups (Figure S1), but given the inherent flexibility of the iso-propyl substitutents, the energies for interconversion 


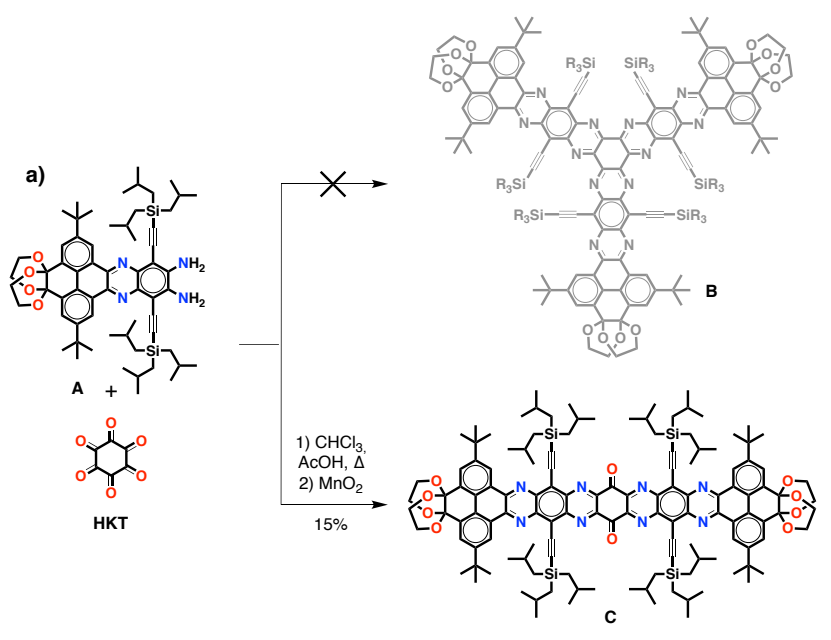

b)
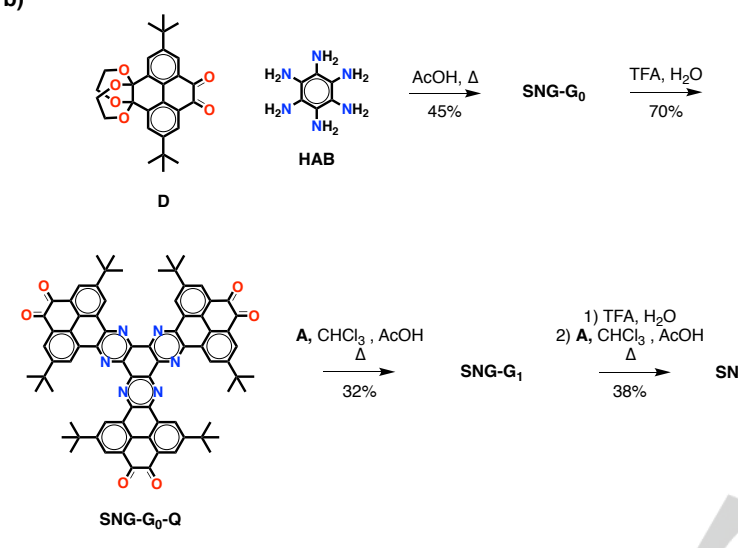

Scheme 1. a) Attempted synthesis of precursor $\mathbf{B}$, leading to compound $\mathbf{C}$ instead. b) Synthesis of $\mathbf{S N G}-\mathbf{G}_{0}, \mathbf{S N G}-\mathbf{G}_{\mathbf{1}}$ and $\mathbf{S N G}-\mathbf{G}_{\mathbf{2}}$.

between conformations are very small, which gives rise to nearly planar structures on average. The simulations show that the SNGs possess stable disk structures with diameters of $1.7,4.1$

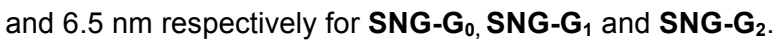

The absorption spectra of the SNGs were recorded in $\mathrm{CHCl}_{3}$ and showed sets of absorption bands also consistent with their structure (Figure 2b). The electronic absorption spectrum of SNG-G $\mathbf{G}_{0}$ is dominated by 3 bands at 357,402 and $428 \mathrm{~nm}$, with a molar attenuation coefficient of $\left(68,429 \mathrm{Lmol}^{-1} \mathrm{~cm}^{-1}\right)$ for the longest wavelength transition (Figure $2 \mathrm{~b}$ ). The absorption bands of SNG-G $\mathbf{H}_{1}(354,525$ and $604 \mathrm{~nm})$ and SNG-G 2 (373, 541 and $605 \mathrm{~nm}$ ) appear bathochromically shifted in comparison with those of SNG-G $\mathbf{G}_{0}$ as consequence of the extension in the effective conjugation, which allows identifying three main absorption bands with their corresponding vibronic features. These were assigned as the $\alpha, \rho$ and $\beta$ bands from longer to shorter wavelengths (Figure $2 b$ ), in agreement with previous assignments on pyrene-fused systems. ${ }^{[4,11 b, 12]}$ The spectra showed that while the $\alpha$ band remains at almost invariable energies, the $\beta$ and the $\rho$ bands are increasingly shifted towards lower energies as a result of the radial extension of the $\pi$ system. Remarkably, also the molar absorptivity $(\varepsilon)$ increases together with the diameter of the SNG, as exemplified by comparing the $\rho$ bands of SNG-G $\left(448,985 \mathrm{Lmol}^{-1} \mathrm{~cm}^{-1}\right)$ and
SNG-G $2\left(629,021 \mathrm{Lmol}^{-1} \mathrm{~cm}^{-1}\right)$. The experimental electronic absorption spectra are in agreement with the calculated ones, which do not only corroborate the electronic structure but also shine light on the nature of the electronic transitions (Figure S2 and Tables S1-S3). In fact, time-dependent density functional theory (TD-DFT) and frontier orbital energies were computed with the 6-31 $\mathrm{g}(\mathrm{d})$ basis set with the B3LYP Hamiltonian for SNG$\mathbf{G}_{0}-\mathbf{H}$, SNG-G $\mathbf{-}-\mathbf{H}$, and $\mathbf{S N G}-\mathbf{G}_{2}-\mathbf{H}$, in which the TIBS groups on the acetylenes have been replaced by $\mathrm{H}$ atoms in order to reduce the calculation time due to the large size of the SNGs. The calculations show absorption spectra with the same trends as the experimental ones in terms of energies and intensities, in which the spectrum of SNG-G $\mathbf{G}_{0}-\mathbf{H}$ also differs from the spectra of SNG-G $\mathbf{G}_{1}-\mathbf{H}$ and SNG-G $-\mathbf{H}$ (Figure S2). The simulated spectrum of SNG-G $-\mathbf{H}$ confirms that the $\alpha, \rho$ and $\beta$ bands are overlapped. The first lower energy band in SNG-G $\mathbf{H}-\mathbf{H}$ and $\mathbf{S N G}-\mathbf{G}_{2}-\mathbf{H}$ consistent with the experimental $\alpha$ band - originates from transitions between the degenerate HOMOs and LUMOs (Figure

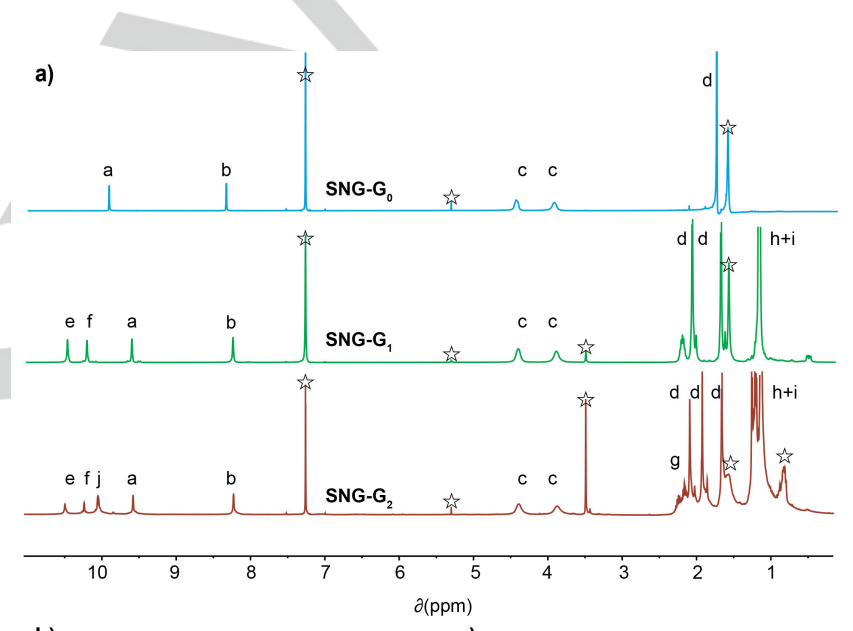

b)

c)
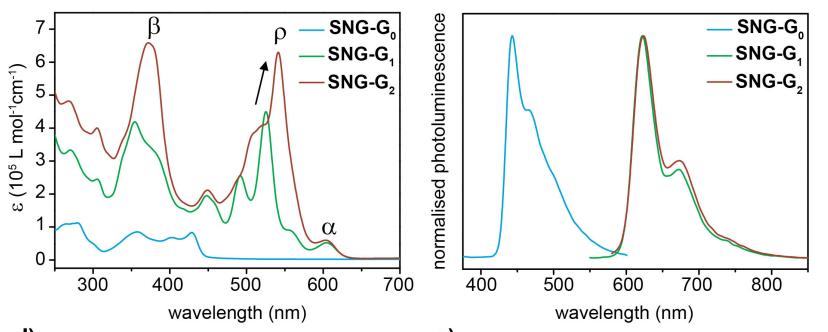

d)

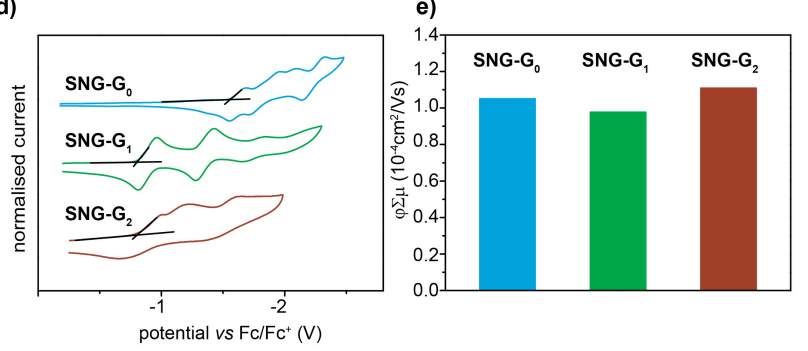

Figure 2. a) ${ }^{1} \mathrm{H}-\mathrm{NMR}$ spectra in $\mathrm{CDCl}_{3}$. The assignments correspond to the lettering in Figure 1. The stars indicate residual solvent peaks. b) UV-vis electronic absorption and c) photoluminescence spectra in $\mathrm{CHCl}_{3}$. d) Cyclic voltammograms in an Ar-saturated $0.1 \mathrm{M}$ solution of $n \mathrm{Bu}_{4} \mathrm{NPF}_{6}$ in $\mathrm{CH}_{2} \mathrm{Cl}_{2}$. Potentials versus Fc/Fc ${ }^{+}$. e) TRMC $\left(\lambda=355 \mathrm{~nm}, \mathrm{I}_{0}=9.1 \times 10^{15}\right.$ photons $\left./ \mathrm{cm}^{2}\right)$. 
S4). The second band - consistent with the experimental $\rho$ band - originates from the transitions between a set of lower energy non-frontier degenerate $\mathrm{HOMO}$ orbitals (HOMO-3 and HOMO-4

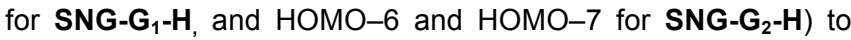
the degenerate LUMOs (Figure S5).

Remarkably, all three SNGs are emissive regardless of their size and their photoluminescence spectra are also consistent with their electronic structure. The emission spectrum of SNG-G $\mathbf{G}_{0}$ in $\mathrm{CHCl}_{3}\left(\lambda_{\mathrm{ex}}=340 \mathrm{~nm}\right)$ exhibited a band at $443 \mathrm{~nm}$ (quantum yield $\left.(\Phi)=0.26^{[13]}\right)$. Meanwhile, the photoluminescence spectra of SNG-G ${ }_{1}$ and SNG-G ${ }_{2}\left(\lambda_{\mathrm{ex}}=524\right.$ and $540 \mathrm{~nm}$, respectively) in $\mathrm{CHCl}_{3}$ show an isoenergetic emission band at $623 \mathrm{~nm}\left(\Phi=0.27\right.$ and $0.15,{ }^{[14]}$ respectively $)$, since the emission originates in both cases from the a absorption band that is diameter independent. However, the emission of SNG-G $\mathbf{G}_{1}$ and $\mathbf{S N G}-\mathbf{G}_{2}$ is bathochromically shifted in comparison to $\mathbf{S N G}-\mathbf{G}_{0}$, as the result of the extended conjugation of the $\pi$-system.

The electrochemical properties of the SNGs were investigated by cyclic voltammetry in $\mathrm{CH}_{2} \mathrm{Cl}_{2}$ with $n \mathrm{Bu}_{4} \mathrm{NPF}_{6}$ as electrolyte (Figure 2d). The voltammograms show several reduction processes, while no oxidation processes were observed within the solvent-electrolyte window. From the cyclic voltammograms of $\mathbf{S N G}-\mathbf{G}_{0}$ four reduction waves could be identified at potentials more negative than $-1.5 \mathrm{~V}$, while only three reduction waves at more positive potentials (between -0.5 and $-2.0 \mathrm{~V}$ ) were identified for $\mathbf{S N G}-\mathbf{G}_{1}$ and $\mathbf{S N G}-\mathbf{G}_{2}$, in agreement with the extended conjugation. The three reduction waves are more anodically shifted and broader in the case of SNG-G $\mathbf{G}_{2}$, which is consistent with both the extended conjugation and the multiple degenerate LUMO orbitals (Figures S3-S5).

We estimated the energy gaps $\left(E_{\text {gap }}\right)$ from the absorption onset of the longest absorption wavelength with values of 2.78, 1.98 and $1.97 \mathrm{eV}$ for SNG-G , SNG-G $_{1}$ and SNG-G $\mathbf{G}_{2}$, respectively. These $E_{\text {gap }}$ values follow the same trends as the theoretical values (B3LYP-6-311+g(2d,g)/B3LYP-6-31g(d)) of SNG-G $-\mathbf{H}, \mathbf{S N G}-\mathbf{G}_{1}-\mathbf{H}$ and $\mathbf{S N G}-\mathbf{G}_{2}-\mathbf{H}$ (Tables S2 and S3). The LUMO levels ( $\left.E_{\text {LUMO }}\right)$ were estimated from the onset of the first reduction potential $\left(E_{\text {LUMO }}=-4.8-\mathrm{e}\left(E_{\mathrm{ONSET}}-E_{1 / 2}{ }^{\mathrm{Fc}}\right)\right)$. The $E_{\text {LUMO }}$ of

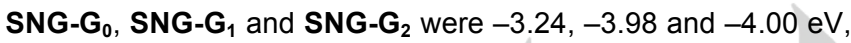
respectively, which match reasonably well in absolute terms and very well in relative terms with the theoretical values (B3LYP-6$311+\mathrm{g}(2 \mathrm{~d}, \mathrm{~g}) / \mathrm{B} 3 \mathrm{LYP}-6-31 \mathrm{~g}(\mathrm{~d}))$ of $\mathbf{S N G}-\mathbf{G}_{0}-\mathbf{H}$, SNG-G $\mathbf{H}_{1}-\mathbf{H}$ and SNG-G $-\mathbf{H}$ (Tables S2 and S3). The HOMO levels $\left(E_{\mathrm{HOMO}}\right)$ have been calculated from the difference between $E_{\mathrm{LUMO}}$ and $E_{\mathrm{g}}$ and were the following: $-6.02,-5.96$ and $-5.97 \mathrm{eV}$ for $\mathbf{S N G}-\mathbf{G}_{0}$, $\mathbf{S N G}_{1}$ and $\mathbf{S N G}-\mathbf{G}_{2}$, respectively.

To assess the charge transporting properties of the SNGs, we performed time-resolved microwave conductivity measurements (TRMC) ${ }^{[15]}$ directly on the solids powders (Figure $2 e$ and Table S4). TRMC allows calculating the pseudophotoconductivity values $\left(\varphi \Sigma \mu_{\max }\right)$, which can be considered the intrinsic or minimum charge carrier mobility of the material, without the need of contacts. For instance the $\varphi \Sigma \mu_{\max }$ values correspond to the sum of the hole and electron mobilities $(\Sigma \mu)$ times the quantum yield $(\varphi)$. We obtained nearly invariable $\varphi \Sigma \mu_{\max }$ values $\left(1.05 \times 10^{-4}, 0.98 \times 10^{-4}\right.$ and $1.11 \times 10^{-4} \mathrm{~cm}^{2} \mathrm{~V}^{-1}$ $\mathrm{s}^{-1}$ for $\mathbf{S N G}-\mathbf{G}_{0}, \mathbf{S N G}-\mathbf{G}_{1}$ and $\mathbf{S N G}-\mathbf{G}_{2}$, respectively), which are similar to those obtained for ribbon-like NGs, ${ }^{[4]} \pi$-gels ${ }^{[16]}$ and conjugated polymers. ${ }^{[17]}$ Similarly, nearly invariable half lifetimes
$\left(\mathrm{T}_{1 / 2}\right)$ of $0.45,0.65$ and $0.50 \mu \mathrm{s}$ for SNG-G , SNG-G $_{1}$ and SNG$\mathbf{G}_{2}$, respectively, were measured. The nearly invariable $\varphi \Sigma \mu$ and $\mathrm{T}_{1 / 2}$ values observed are consistent with observed localized states.

In this work, we have reported the synthesis of highly soluble SNGs with diameters up to $6.5 \mathrm{~nm}$. Their synthesis has been achieved by a careful design and synthesis of a $C_{3}$ symmetrical precursor from which the SNG core is then extended radially. Most importantly, this approach provides highly soluble SNGs, which has allowed their synthesis and purification by solution methods and also a full characterisation $\left({ }^{1} \mathrm{H}\right.$ and ${ }^{13} \mathrm{C}$ NMR, HRMS, UV-vis, photoluminescence, cyclic voltammetry and TRMC) that show how the radial extension of the $\pi$-system results in changes in their electronic absorption, molar absorptivity, photoluminescence and electrochemistry, while other properties remain almost invariable, such as the photoluminescence of the higher SNGs and the charge transport properties. The high molar absorptivity, low LUMO energies and $\varphi \Sigma \mu$ values illustrate the $n$-type semiconducting character and their potential in charge transport and energy conversion applications.

\section{Acknowledgements}

We are grateful to the Basque Science Foundation for Science (Ikerbasque), POLYMAT, the University of the Basque Country (Grupo de Investigación GIU17/054 and SGlker), Gobierno de España (Ministerio de Economía y Competitividad CTQ201677970-R), Gobierno Vasco (BERC programme), the Portuguese Foundation for Science and Technology (IF/00894/2015) and CICECO - Aveiro Institute of Materials, POCI-01-0145-FEDER007679 (FCT Ref. UID /CTM /50011/2013). This project has received funding from the European Union's Horizon 2020 research and innovation programme under grant agreement No 664878 . This project has received funding from the European Research Council (ERC) under the European Union's Horizon 2020 research and innovation programme (grant agreement $n^{\circ}$ 722951).

Keywords: polycyclic aromatic hydrocarbons • nanographenes • starphenes $\cdot$ cloverphenes $\bullet$ star-shaped nanographenes

[1] a) A. Narita, in Synthetic Methods for Conjugated Polymers and Carbon Materials (Eds.: M. Leclerc, J. Morin), Wiley-VCH, 2017; b) A. MateoAlonso, Chem. Soc. Rev. 2014, 43, 6311-6324; c) A. Narita, X.-Y. Wang, X. Feng, K. Müllen, Chem. Soc. Rev. 2015, 44, 6616-6643; d) B. A. G. Hammer, K. Müllen, Chem. Rev. 2016, 116, 2103-2140; e) M. Stępień, E. Gońka, M. Żyła, N. Sprutta, Chem. Rev. 2017, 117, 3479-3716; f) Z. Cai, M. A. Awais, N. Zhang, L. Yu, Chem 2018, DOI: 10.1016/j.chempr.2018.1008.1017.

[2] a) Z. Hua, W. Di, H. L. Sheng, Y. Jun, Curr. Org. Chem. 2012, 16, $2124-$ 2158; b) E. Clar, A. Mullen, Tetrahedron 1968, 24, 6719-6724; c) V. S. Iyer, M. Wehmeier, J. D. Brand, M. A. Keegstra, K. Müllen, Angew. Chem. Int. Ed. 1997, 36, 1604-1607; d) J. Wu, Ž. Tomović, V. Enkelmann, K. Müllen, J. Org. Chem. 2004, 69, 5179-5186; e) Ž. Tomović, M. D. Watson, K. Müllen, Angew. Chem. Int. Ed. 2004, 43, 755-758; f) X.-Y. Cao, H. Zi, W. Zhang, H. Lu, J. Pei, J. Org. Chem. 2005, 70, 3645-3653; g) R. Rieger, M. Kastler, V. Enkelmann, K. Müllen, Chem. Eur. J. 2008, 14, 6322-6325; h) H.-P. Jia, S.-X. Liu, L. Sanguinet, E. Levillain, S. Decurtins, J. Org. Chem. 2009, 74, 5727-5729; i) J. Yin, H. Qu, K. Zhang, J. Luo, X. Zhang, C. Chi, J. Wu, Org. Lett. 2009, 11, 3028-3031; j) Y. Zhang, D. Hanifi, S. Alvarez, F. Antonio, A. Pun, L. M. Klivansky, A. Hexemer, B. Ma, Y. Liu, Org. Lett. 2011, 13, 6528-6531; k) J. M. Alonso, A. E. Díaz-Álvarez, A. Criado, D. Pérez, D. Peña, E. Guitián, Angew. Chem. Int. Ed. 2012, 51, 
173-177; I) B. Schuler, S. Collazos, L. Gross, G. Meyer, D. Pérez, E. Guitián, D. Peña, Angew. Chem. Int. Ed. 2014, 53, 9004-9006; m) E. C. Rüdiger, M. Porz, M. Schaffroth, F. Rominger, U. H. F. Bunz, Chem. Eur J. 2014, 20, 12725-12728; n) C. Cheng, Y. Jiang, C.-F. Liu, J.-D. Zhang, W.-Y. Lai, W. Huang, Chem. Asian J. 2016, 11, 3589-3597; o) C.-F. Liu, C. Cheng, Y. Jiang, W.-Y. Lai, W. Huang, New J. Chem. 2017, 41, 1361913624; p) J. Hieulle, E. Carbonell-Sanromà, M. Vilas-Varela, A. GarciaLekue, E. Guitián, D. Peña, J. I. Pascual, Nano Lett. 2018, 18, 418-423.

[3] a) J. L. Segura, R. Juárez, M. Ramos, C. Seoane, Chem. Soc. Rev. 2015 44, 6850-6885; b) T. Wöhrle, I. Wurzbach, J. Kirres, A. Kostidou, N. Kapernaum, J. Litterscheidt, J. C. Haenle, P. Staffeld, A. Baro, F. Giesselmann, S. Laschat, Chem. Rev. 2016, 116, 1139-1241; c) X.-Y. Yan, M.-D. Lin, S.-T. Zheng, T.-G. Zhan, X. Zhang, K.-D. Zhang, X. Zhao, Tetrahedron Lett. 2018, 59, 592-604; d) C. Peng, G.-H. Ning, J. Su, G. Zhong, W. Tang, B. Tian, C. Su, D. Yu, L. Zu, J. Yang, M.-F. Ng, Y.-S. Hu, Y. Yang, M. Armand, K. P. Loh, Nat. Energy 2017, 2, 17074; e) N. Wang K. Zhao, T. Ding, W. Liu, A. S. Ahmed, Z. Wang, M. Tian, X. W. Sun, Q. Zhang, Adv. Energy Mater. 2017, 7, 1700522.

[4] D. Cortizo-Lacalle, J. P. Mora-Fuentes, K. Strutyński, A. Saeki, M. MelleFranco, A. Mateo-Alonso, Angew. Chem Int. Ed. 2018, 57, 703-708.

[5] D. Z. Rogers, J. Org. Chem. 1986, 51, 3904-3905.

[6] S. Miao, A. L. Appleton, N. Berger, S. Barlow, S. R. Marder, K. I. Hardcastle, U. H. F. Bunz, Chem. Eur. J. 2009, 15, 4990-4993.

[7] S. Choudhary, C. Gozalvez, A. Higelin, I. Krossing, M. Melle-Franco, A Mateo-Alonso, Chem. Eur. J. 2014, 20, 1525-1528.
[8] a) C. Wang, J. Zhang, G. Long, N. Aratani, H. Yamada, Y. Zhao, Q. Zhang, Angew. Chem. Int. Ed. 2015, 54, 6292-6296; b) D. Cortizo-Lacalle, C. Gozalvez, M. Olano, X. Sun, M. Melle-Franco, L. E. Hueso, A. MateoAlonso, Org. Lett. 2015, 17, 5902-5905.

[9] R. García, M. Melle-Franco, A. Mateo-Alonso, Chem. Commun. 2015, 51, 8037-8040.

[10] ${ }^{1} \mathrm{H}-\mathrm{NMR}$ does not show any evidence of the presence dihydro species during the cyclocondensation. For instance when SNG-G $\mathbf{G}_{2}$ was exposed to Bunz oxidation conditions no change of colour was observed, which confirms that the aromatic core is fully aromatised.

[11] a) S. Grimme, C. Bannwarth, P. Shushkov, J. Chem. Theory. Comput 2017, 13, 1989-2009; b) D. Cortizo-Lacalle, C. Gozalvez, M. Melle-Franco, A. Mateo-Alonso, Nanoscale 2018, 10, 11297-11301.

[12] E. Clar, The Aromatic Sextet, Wiley, London, 1972.

[13] Estimated using 9,10-diphenylanthracene in hexane as a reference.

[14] Estimated using oxazine in $\mathrm{MeOH}$ as a reference.

[15] A. Saeki, Y. Koizumi, T. Aida, S. Seki, Acc. Chem. Res. 2012, 45, 11931202.

[16] M. Martínez-Abadía, G. Antonicelli, A. Saeki, A. Mateo-Alonso, Angew. Chem. Int. Ed. 2018, 57, 8209-8213.

[17] A. Saeki, S.-i. Ohsaki, S. Seki, S. Tagawa, J. Phys. Chem. C 2008, 112, 16643-16650.

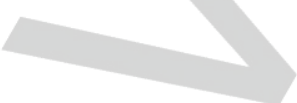




\section{COMMUNICATION}

Giant stars! A new family of giant star-shaped N-doped nanographenes with diameters up to $6.5 \mathrm{~nm}$ is reported.
Juan P. Mora-Fuentes, Alberto RiañoCarnerero, Diego Cortizo-Lacalle, Akinori Saeki, Manuel Melle-Franco, * Aurelio Mateo-Alonso*

\section{Page No. - Page No.}

Giant Star-shaped Nitrogen-doped Nanographenes

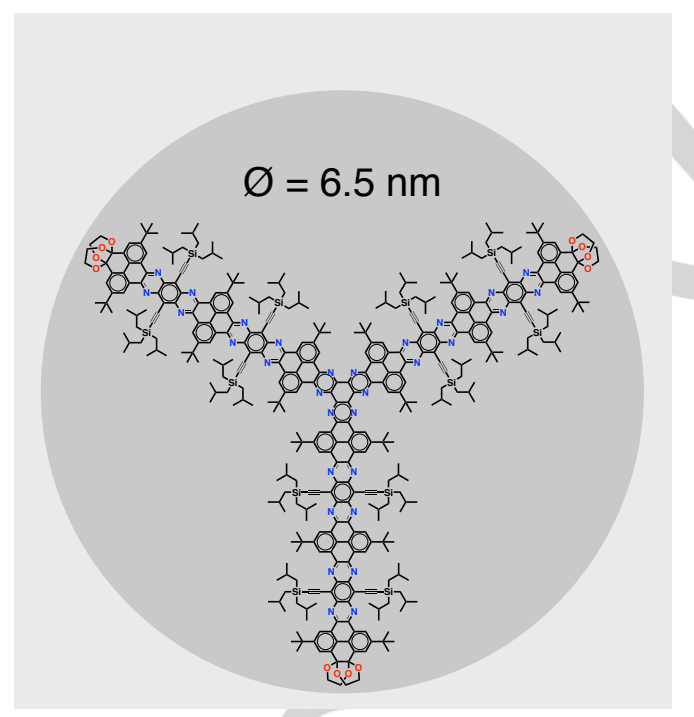

